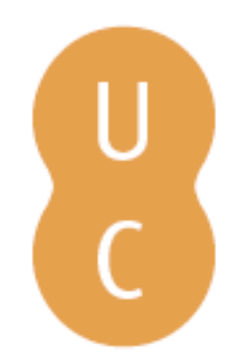

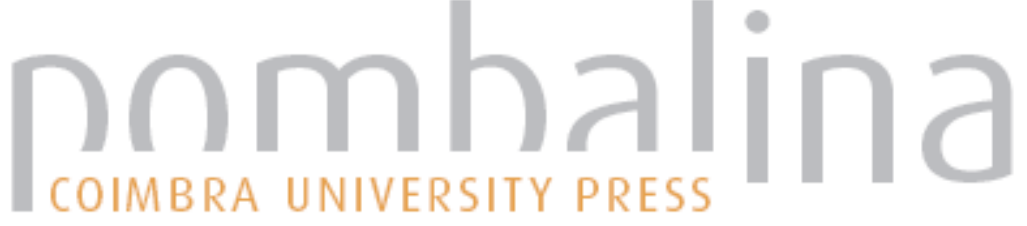

\section{Fenomenologia: a metafísica do método}

\author{
Autor(es): $\quad$ Alves, Pedro M. S.
}

Publicado por: Imprensa da Universidade de Coimbra

URL

persistente: URI:http://hdl.handle.net/10316.2/32233

DOI: $\quad$ DOI:http://dx.doi.org/10.14195/978-989-26-0361-2_7

Accessed : $\quad$ 26-Apr-2023 15:08:35

A navegação consulta e descarregamento dos títulos inseridos nas Bibliotecas Digitais UC Digitalis, UC Pombalina e UC Impactum, pressupõem a aceitação plena e sem reservas dos Termos e Condições de Uso destas Bibliotecas Digitais, disponíveis em https://digitalis.uc.pt/pt-pt/termos.

Conforme exposto nos referidos Termos e Condições de Uso, o descarregamento de títulos de acesso restrito requer uma licença válida de autorização devendo o utilizador aceder ao(s) documento(s) a partir de um endereço de IP da instituição detentora da supramencionada licença.

Ao utilizador é apenas permitido o descarregamento para uso pessoal, pelo que o emprego do(s) título(s) descarregado(s) para outro fim, designadamente comercial, carece de autorização do respetivo autor ou editor da obra.

Na medida em que todas as obras da UC Digitalis se encontram protegidas pelo Código do Direito de Autor e Direitos Conexos e demais legislação aplicável, toda a cópia, parcial ou total, deste documento, nos casos em que é legalmente admitida, deverá conter ou fazer-se acompanhar por este aviso.

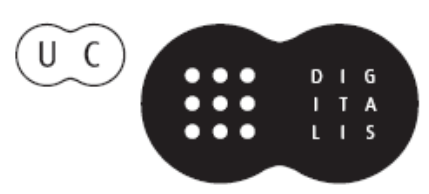


Diogo Ferrer

Coordenação

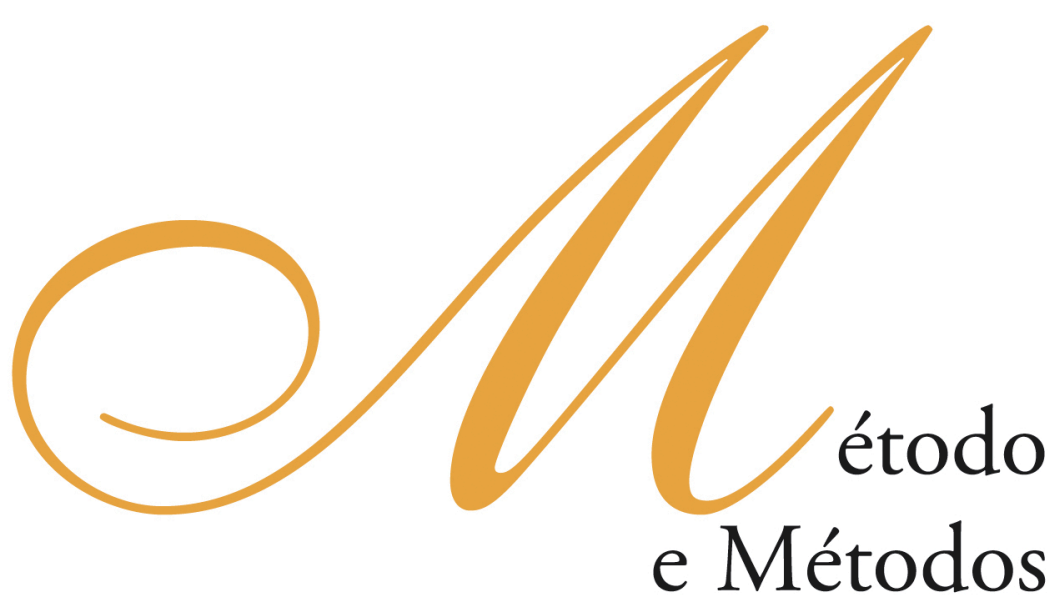

do Pensamento Filosófico 


\section{COORDENAÇÃO EDITORIAL \\ Imprensa da Universidade de Coimbra}

URL: http//www.imp.uc.pt

\section{CONCEPÇÃO GRÁFICA}

António Barros

PRÉ-IMPRESSÃO

Victor Hugo Fernandes

EXECUÇÃO GRÁFICA

Inova - Artes gráficas

ISBN

989-8074-02-7

DEPÓSITO LEGAL

$257236 / 07$

(C) Março 2007, Imprensa da Universidade de Coimbra

OBRA PUBLICADA COM O APOIO DE:

Centro de Estudos Clássicos e Humanísticos

FCT Fundação para a Ciência e a Tecnologia MINISTÉRIO DA CIÊNCIA E DA TECNOLOGIA 
Diogo Ferrer

Coordenação

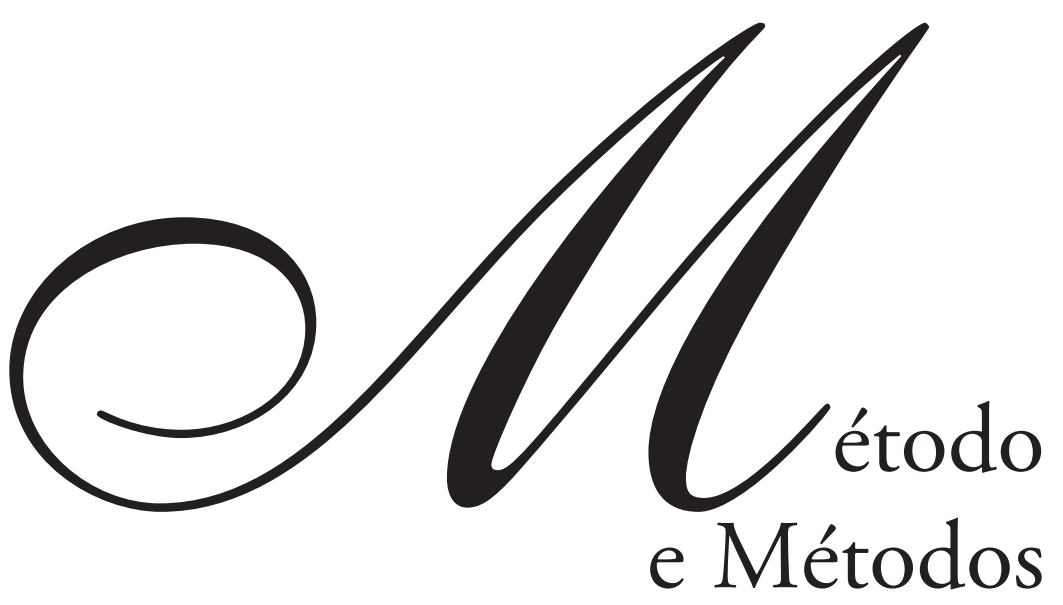

do Pensamento Filosófico

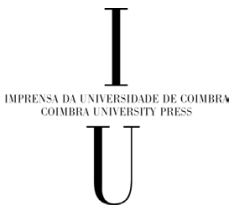

- COIMBRA 2007 

Pedro M. S. Alves

Universidade de Lisboa

Fenomenologia: A Metafísica do Método

Frequentemente, a Fenomenologia de Husserl é identificada com um método. A parafernália das «reduções», a eidética e a transcendental, as técnicas da epoche e da parentetização, a questiúncula dos «caminhos», o cartesiano e os outros, pela Ontologia e pela Psicologia, são, muitas vezes, aquilo que se retém, aquilo que se apresenta e aquilo que se discute como conteúdo positivo da Fenomenologia.

Todavia, a Fenomenologia não é um método. Pelo contrário, há um método fenomenológico. Isso significa que é o conceito de Fenomenologia que esclarece e fundamenta o método e não, ao invés, o método que esclarece e determina o sentido da Fenomenologia. O conceito de Fenomenologia não pode, pois, ser esclarecido pelo de método. Todos os comentários sobre as reduções, sobre a parentetização ou sobre as demais operações, se não forem efectuados por regresso ao conceito de Fenomenologia, acabam por secar a fonte que a alimenta e por a reduzir a pouco mais que uma técnica.

O conceito de Fenomenologia não pode, por outro lado, ser bem compreendido por uma simples definição nominal. Se definimos, literalmente, Fenomenologia como a "ciência dos fenómenos", importa, de seguida, esclarecer o que seja um "fenómeno" no sentido da Fenomenologia. E de novo somos remetidos para um conceito de Fenomenologia que já está 
pressuposto na simples definição nominal. Pressuposto, há que sublinhá-lo, mas não ainda explicitado e esclarecido no seu efectivo teor. Poder-se-á sempre apelar à erudição, quando nos falha uma efectiva penetração. Podemos confrontar a concepção husserliana de Fenomenologia com a concepção hegeliana, ou mesmo com a de Lambert e de Kant, deixando-nos guiar pela simples identidade do nome, para, logo de seguida - como seria, aliás, de esperar —, "descobrirmos», por detrás dessa identidade nominal, uma divergência substantiva que não estamos, no entanto, em condições de fixar conceptualmente de um modo satisfatório. Se esse caminho longo da erudição filosófica é, como sucede as mais das vezes, uma manobra para contornar a necessidade de ponderação do próprio conceito de Fenomenologia, então toda a erudição histórica e sistemática, com o seu estilo copioso e os seus tiques de métier, será pouco mais que uma encenação no vazio.

Há, porém, um último recurso sempre à mão. Ele é o mais comummente utilizado. A Fenomenologia é uma teoria da «intencionalidade», diz-se. Isso é, de facto, o que a fenomenologia husserliana efectivamente pensa, o seu tema ou conteúdo positivo. Mas isso não responde ainda à questão: que pretende a Fenomenologia pensar através do seu tema director da intencionalidade, que questão pretende ela tratar por meio do regresso temático à intencionalidade da consciência? Como Heidegger bem viu, mais que um santo-e-senha capaz de abrir todas as portas, a «intencionalidade» é, antes, o título de um problema central. Penetrar na Fenomenologia significa regredir até a questão que a intencionalidade pretende pensar, e compreender, retrospectivamente, o próprio conceito do intencional a partir dessa questão de fundo. Distinguiremos, portanto, entre aquilo que a Fenomenologia pensa, ou seja, tanto o seu tema positivo como o método que lhe dá acesso, e o horizonte problemático em que ela, com isso, pretende penetrar, a questão fundamental que a convoca e que rege, muitas vezes surdamente, tanto a determinação positiva do seu campo temático como as decisões metodológicas que lhe dão acesso. 
Esse campo só é, contudo, acessível pelo modo como ele se repercute na circunscrição do tema da Fenomenologia e na elaboração do método fenomenológico. Ele pode ler-se a partir daí, como aquela instância que determina a circunscrição da intencionalidade como tema positivo da Fenomenologia e que comanda as decisões relativas ao método, enquanto técnica de análise apontada à exibição das estruturas intencionais da consciência.

Esse campo em que a Fenomenologia se inscreve, e a partir do qual é possível uma elaboração do seu conceito, não é uma construção interpretativa destinada a pôr em destaque aquilo que, em Husserl, teria ficado ainda nebulosamente encoberto. Pelo contrário, numa carta a Dilthey, de 1911, Husserl apresenta-o com toda a nitidez. As suas palavras são as seguintes: "Que haja, por princípio, necessidade de uma Metafísica assim entendida, perante as ciências da natureza e do espírito, tal como foram desenvolvidas pelo imenso trabalho da Modernidade, a razão disso é que a própria essência do conhecimento implica uma sobreposição de dois estratos e, por isso mesmo, uma dupla atitude cognitiva, uma simplesmente orientada para o Ser tal como é visado pelo conhecimento, pensado de tal ou tal maneira e fenomenicamente dado, a outra, orientada, ao contrário, para a misteriosa relação essencial entre Ser e Consciência. Todo conhecimento natural das realidades presentes, todo conhecimento efectuado de acordo com a primeira atitude deixa aberta uma dimensão de problemas cuja solução é requerida para que se possa chegar a uma determinação última e definitiva do sentido do Ser [...]. Creio poder reconhecer que, por detrás dos problemas do Ser entendidos de uma forma acabada, ou seja, incluindo igualmente a "constituição" do Ser na consciência, não pode haver outros problemas que tenham ainda uma significação, que, por conseguinte, [...] 
não há lugar para nenhuma outra ciência, e que falar de um Ser que estaria ainda por detrás e que seria incognoscível é, por princípio, absurdo».(1)

O método fenomenológico é um dispositivo para remontar do dado até a origem da sua significação na consciência; a exibição dos actos em que essa significação se constitui é um esclarecimento da intencionalidade, na sua estrutura e legalidade próprias; e a intencionalidade é, por sua vez, o modo de a Fenomenologia penetrar e tratar sistematicamente o problema da "relação essencial entre Ser e Consciência», ou, numa linguagem que também é a de Husserl, o problema metafísico da relação entre Pensar e Ser. E isso de uma forma, como a carta bem frisa, acabada, ou seja, pensando a conexão entre Ser e Consciência como última. Deste modo, um Ser mais além da sua aparição, e que a ela se furtasse como um «em si» ignoto e impenetrável, será, doravante, apresentado como um conceito absurdo, um conceito que, segundo a lição das Logische Untersuchungen, será um contra-senso (Widersinn, não Unsinn) internamente tão contraditório como o de "quadrado redondo" ou de "madeira de ferro".

Colocar o método fenomenológico no horizonte da questão de fundo que o rege, esclarecê-lo a partir dela e ver nele, em retorno, uma determinação dessa mesma questão, é, precisamente, aquilo que designamos, aqui, a Metafísica do Método. É nossa convicção que o trajecto intelectual de Husserl pode ser fixado em quatro momentos principais. Não se trata propriamente de quaisquer "fases» no desenvolvimento da Filosofia de Edmund Husserl,

(1) "Dass es einer Metaphysik in diesem Sinne prinzipiell bedarf, gegenüber den in der grossen Arbeit der Neuzeit erwachsenen Natue- und Geisteswissenschaften, hat darin seine Quelle, dass im Wesen der Erkenntnis eine Schichtung, und damit zusammenhängend eine doppelte Erkenntnisstellung begründet ist: die eine rein auf das Sein gerichtet, das bewusstseinsmässig gemeint, so und so gedacht und erkenntnismässig gegeben ist, die andere aber gerichtet auf die rätselhaften Wesensbeziehungen zwischen Sein und Bewusstsein. Alle natürliche Daseinserkenntnis, alle Erkenntnis innerhalb der ersten Einstellung, lässt eine Dimension von Problemen offen, von deren Lösung die letzte Auswertung der in der "natürlichen» Einstellung vermeintlich schon erreichen Wahrheit abhängt. Ich glaube eisehen zu können, dass es hinter den vollständigen, d. H. Die "Constitution» des Seins im Bewusstsein mit einbeziehenden Seinsproblemen, sinvoll keine mehr geben kann, dass also hinter der phänomenologisch erweiterten und fundierten [universalen] Daseinswissenschaft [...] keine Wissenschaft mehr liegen kann, bezw. Dass von einem noch dahinter liegenden, prinzipiell unerkennbaren Sein zu sprechen, Widersinn ist». Husserl an Dilthey, 5-6 de Julho de 1911, Briefwechsel, VI, Band, p. 50. 
no sentido do artigo clássico de Walter Biemel. ${ }^{(2)}$ Os motivos circunstanciais do pensamento de um autor, o modo como certos conceitos se formaram, se alargaram e se estenderam a outros temas, cuja actualidade se deixa, por sua vez, explicar pelas circunstâncias envolventes, toda essa matéria de intricadas conexões e de fios-condutores no desenvolvimento do pensamento de um autor, é assunto que não nos interessará aqui. Pelo contrário, em vez de "fases», que sempre deixam supor uma transformação de um conteúdo numa nova forma e um balanço sobre as semelhanças e diferenças entre o ponto de partida e o ponto de chegada, em vez de "fases», neste sentido metamórfico, julgamos que há momentos sucessivos de aprofundamento e de radicalização de um único pensamento fundamental, pensamento que se inscreve na Metafísica do Método fenomenológico e que comanda as suas sucessivas reformulações. De facto, Husserl sempre apresentou as suas obras principais como reformulações da Fenomenologia. Foi assim para as Logische Untersuchungen, se as pusermos em relação com o seu "psicologismo" anterior, foi também assim para Ideen, relativamente a Logische Untersuchungen, para Formale und Transzendentale Logik, relativamente às duas primeiras, e, finalmente, para Die Krisis. Não há, para Husserl, na sua autocompreensão, tanto a ideia de um percurso que se desenvolvesse em sucessivas fases, de tal modo que cada uma seria necessária para a consecução das subsequentes, mas antes a de um único conceito - o de Fenomenologia - que se aprofunda, se reformula, se elabora numa nova operação do método e que vem tornar caducas, a título de formas ainda imaturas, todas as apresentações anteriores.

(2) Walter Biemel - «Les phases décisives dans le développement de la philosophie de Husserl.. In Cahiers de Royaumont. Philosophie, n. ${ }^{\circ}$ III. Paris: Les Éditions de Minuit, 1959, pp. 32-59. 
A primeira elaboração do conceito de Fenomenologia pode ser condensada na tese seguinte: para todo ser, qualquer que ele seja, há sempre um modo pelo qual ele pode ser dado (gegeben) a uma consciência possível.

Trata-se de uma tese compreensível por si mesma, incontroversa, mas, por isso mesmo, de uma tese ainda fraca. Em substância, ela estatui apenas que, para qualquer real, não importa o que em si mesmo seja e as leis que regulam a sua génese e a sua constituição como um ser, para qualquer real $X$, haverá sempre um modo pelo qual ele pode ser dado a uma consciência possível e se vem inserir, assim, como objecto na vida representativa de um sujeito. Trata--se de descrever esses modos. O conceito director que organiza esta primeira formulação da Fenomenologia é o de doação (Gegebenheit). A Fenomenologia não é, assim, uma teoria ontológica do objecto, mas uma disciplina que enceta um regresso dos objectos até os modos diversos do seu ser-visado e do seu ser-dado, que são sempre acontecimentos na vida representativa da consciência. A Fenomenologia é, portanto, uma teoria dos actos de consciência e dos caracteres que os diferenciam, primeiro, relativamente aos seus constituintes de matéria intencional e qualidade posicional, depois, quanto aos modos da sua relação à vivência intuitiva correspondente. Estes últimos modos vão da consciência simbólica, como o caso das operações aritméticas e lógicas realizadas cegamente sobre signos, sem intelecção (Einsicht), à consciência signitiva, que visa uma objectividade "no vazio", a partir da significação (Bedeutung) de um acto linguístico, até o ponto culminante em que a intenção signitiva se vem preencher num acto cujo sentido é o da presença do objecto visado, ou seja, a sua doação (Gegebenheit). Este momento culminante da intencionalidade, como síntese de preenchimento entre um acto signitivo e um acto intuitivo, é o que Husserl designa como o momento da evidência (Evidenz). Ela é o momento de realização da vivência de conbecimento. 
Esta determinação do conceito de Fenomenologia é a que subjaz à primeira grande obra de Husserl, as Logische Untersuchungen. A sua ideia reitora é a seguinte: a Fenomenologia é uma descrição dos actos de consciência, guiada pelo fio-condutor da relação dos actos com um objecto - em que a doação funciona como conceito limite - e a consciência de que aqui se fala, a consciência que está tematicamente em questão, é uma realidade de natureza psicológica. Não será, pois, de estranhar que o nome da Fenomenologia, nessa primeira obra de Husserl, seja o de Psicologia Descritiva. Husserl combate a identificação da Fenomenologia não com a Psicologia, mas com uma psicologia genética e causal. Enquanto esta última se ocupa das leis que regulam o acontecer dos fenómenos psíquicos, fala de faculdades, de leis de associação, e coisas semelhantes, enquanto a Psicologia Genética se ocupa da génese do próprio psíquico a partir dos fundos somáticos do organismo, a Psicologia Descritiva faz, nas palavras do próprio Husserl, abstracção metódica de tudo isso e concentra-se apenas na estrutura dos actos em que as objectividades de toda a espécie são visadas e dadas. Tratava-se, pois, para Husserl, de fazer abstracção das leis naturais e causais que regulam o psíquico e de considerar a estrutura pura da consciência de objectos, no seu teor próprio e nos seus ingredientes de sentido.

A operação metódica que dá acesso a esta teoria da consciência em sede psicológica é a redução eidética, aplicada sobre os actos intencionais e destinada a tornar patente a sua estrutura essencial própria. Ela caracterizava-se por uma tripla operação de idealização: (3) primeiro, a que vai da vivência psíquica na sua existência factual e contingente, por exemplo, um acto judicativo particular, até a espécie de acto correspondente, o julgar enquanto tal; depois, a que converte a espécie de acto numa singularidade ideal, por exemplo, a significação enquanto tal; por fim, a que converte estas singularidades ideais num sistema fechado sobre si, que possui uma

(3) Sobre as três idealizações, aqui desenvolvidas num sentido diferente, ver a boa exposição de B. Smith - «Logic and Formal Ontology». Husserl's Phenomenology. Washington: University Press of America, 1989, p. 30. 
completude também ela ideal, nomeadamente, as leis de composição entre as significações, sob a forma de uma gramática pura lógica, enquanto teoria apriorística das formas e da sintaxe das significações.

Foi matéria de controvérsia saber se, nas Logische Untersuchungen, o conceito de Fenomenologia era ou não compatível com um realismo ao nível dos supostos ontológicos. É possível encontrar passos que vão numa e noutra direcção, de modo que a questão, seja ao nível da sua base textual, seja ao nível da interpretação global, permanece indecidível. A razão profunda para isso é, em nossa opinião, o facto de a Fenomenologia das Logische Untersuchungen ser neutra relativamente a qualquer comprometimento ontológico. Ela é uma teoria dos actos em espécie, ou seja, como unidades ideais. Relativamente à realização dos actos numa vida psíquica concreta e à inserção dessa vida psíquica num fundo somático e do corpo num mundo material, a Fenomenologia não faz qualquer asserção nem discute o bem fundado de quaisquer asserções ontológicas sobre a conexão a estabelecer entre Ser e Consciência. Ou melhor, ela fá-lo, mas de um modo lasso. Se há uma consciência, então o real, seja o que for em si mesmo, tem de poder ser dado em actos representativos, que têm uma estrutura legal própria. Mas é possível que nenhuma consciência psicológica esteja presente, não só circunstancialmente, como em geral, e que, por conseguinte, os actos representativos possíveis não tenham uma base material para se efectivarem.

Apenas um constrangimento está presente nesta conexão, ainda lassa, entre Ser e Consciência. Ele actuará como mola propulsora em direcção a uma ulterior radicalização da Fenomenologia. Trata-se da crítica programática a que Husserl submete a teoria dos signos ou das imagens na percepção. Dado um real $X$ transcendente (não se trata de um objecto ideal), então a sua doação a uma consciência possível é a vivência de percepção (Wahrnehmung). Esta, ou seja, a consciência perceptiva, tem uma estrutura eidética pura e, portanto, uma legalidade própria. Se fazemos variar as estruturas psíquicas dos seres capazes de percepcionar, por exemplo, indo da consciência humana 
até outro tipo de consciência cujo conceito podemos formar, então parece que também o modo de percepção deve variar em conformidade, de modo que percepcionar um mesmo real $X$ seria diferente, consoante as organizações psíquicas próprias dos seres que percepcionam. Esta teoria faz, porém, do objecto dado no acto perceptivo uma simples «imagem mental», subjectiva, imanente à consciência que percepciona. É esta teoria que Husserl combate acerrimamente. Por duas razões. Primeiro, confundir a legalidade pura da vivência perceptiva, como espécie de acto, com a organização particular de um ser psíquico seria fazer do a priori um a posteriori, e cair, em consequência, no vício psicologista de rebater as leis puras da consciência de objectos nas leis contingentes do psiquismo de indivíduos determinados. Essa passagem está, porém, interdita, para Husserl, desde que a Fenomenologia, enquanto Psicologia Descritiva, foi nitidamente separada de quaisquer psicologias de feição genética e causal. Segunda razão, a doação de um objecto tem o sentido de uma presentação da própria coisa visada, e não o de uma imagem mental, pela intermediação da qual se inferiria a presença de um real $X$, a distinguir da sua doação perceptiva a um acto de consciência. O sentido da doação é de ser presença da própria coisa, e não de uma imagem ou de um signo que denotasse a sua existência e que pudesse variar consoante variam as organizações psíquicas dos seres capazes de percepção. Por via disso, se a existência de uma consciência não é requerida pela existência de um real $X$, o modo como ele pode ser dado é, porém, único e sempre o mesmo para quaisquer consciências possíveis. Não tem, pois, sentido distinguir entre objecto intencional e objecto real - as coisas que aparecem mostram-se naquilo que são. O objecto intencional é o objecto real, e a sua doação perceptiva concreta exemplifica uma legalidade que se aplica de um modo universal para todos os seres que possam percepcionar, seja quem for que percepcione e, em geral, pense, seja esse ser um homem, 
um animal, Deus ou um anjo. ${ }^{(4)}$ Esta posição há-de emergir na sua forma madura nas Ideen, de 1913, mas, aí, no quadro de uma segunda radicalização do conceito de Fenomenologia.

A Fenomenologia não trata, pois, dos objectos de que há consciência, mas da consciência de objectos; ela é uma teoria exclusivamente noética da intencionalidade, A sua pretensão é exibir as leis universais que governam toda e qualquer consciência possível de objecto. Todo $X$ deve ter um modo de doação para uma consciência, e esse modo é uma legalidade universal para todos os seres que possam pensar. Como o dirá Husserl em Ding und Raum, não interessa quem pensa, mas o que seja pensar um objecto.

\section{III}

O segundo momento de radicalização do conceito de Fenomenologia pode ser expresso na seguinte tese: um ser só é pensável como correlato de uma constituição (Konstitution) numa e por uma consciência actual.

A publicação recente, como volume XXXVI da Husserliana, de manuscritos que vão de 1908 a 1921, reunidos sob o título Transzendentaler Idealismus, (5) permite surpreender, a partir de 1908, esta radicalização do conceito de Fenomenologia.

A tese de fundo que nesses textos se desenvolve, se explicita e justifica é a de que, em geral, a existência de um mundo não é pensável sem referência a uma consciência actual. Muitas são as versões desta tese de fundo. Por exemplo: «Se não há nenhuma consciência, o ser dos factos reais, das coisas, dos eu perde o seu sentido, e, com isso, também o ser das formas

(4) «Man braucht es nur auszusprechen, und jedermann muss es anerkennen: dass der intentionale Gegenstand der Vorstellung derselbe ist wie ihr wirklicher und gegebenenfalls ihr äusserer Gegenstand und dass es widersinnig ist, zwischen beiden zi unterscheiden. Der transzendente Gegenstand wäre gar nicht Gegenstand dieser Vorstellung, wenn er nicht ihr intentionaler Gegenstand wäre». Hua XIX/1, p. 439.

(5) Transzendentaler Idealismus. Dordrecht: Kluwer Academic Publishers, 2003; Hua XXXVI. 
de realidade». "A asserção: 'a coisa é' não tem qualquer sentido quando se quer negar a consciência actual». (6) Esta tese encontra na designação idealismo transcendental a sua caracterização: «O idealismo transcendental diz: uma Natureza não é pensável sem sujeitos co-existentes, que tenham dela uma experiência; não basta possíveis sujeitos de experiência». (7)

Todo Ser é um ser-posto, ele remete, assim, não para uma consciência possível, mas para uma consciência actual, que tem dele uma experiência. A existência de um real $X$ implica, no seu próprio conceito, uma retro-referência à experiência em que esse real está dado, e à via de consciência em que essa experiência se desenvolve. Não há Ser antes ou fora da sua aparição. Todo Ser é um gesetzt Sein, esse estar-posto reenvia para uma Setzung des Seins, e esta, mais atrás ainda, para uma vida de experiência em que essa posição se efectiva. Tal é o pensamento fundamental de Husserl a partir de 1908. Podemos aferi-lo figurando-nos, em pensamento, um real, que é o que é, e suspendendo a posição de uma consciência actual que aí se insira como vida de experiência. Ora este real, que será «em-si», supostamente sem conexão com uma consciência, é ainda pensado por nós, nesta vida de consciência actual, de tal modo que o "olho" da consciência, por assim dizer, está ainda sempre presente e operante na figuração desse real pretensamente fechado sobre o seu ser autárcico. Ele é, ainda e sempre, para alguém. Podemos objectar que esta é uma necessidade de pensamento, e que, se é certo que não podemos conceber um Ser sem conexão com uma Consciência que actualmente o pense, podemos, no entanto, suprimir o nosso próprio pensamento para quem essa impossibilidade se manifesta, de modo que a contradição desaparece e só resta o próprio real $X$, liberto de toda a conexão. Mas o que restará, então, sob este conceito de um Ser

(6) "Ist kein Bewusstsein, so verliert das Sein von realen Tatsachen, von Dingen, von Ich seinen Sinn, und somit auch das Sein von Realitätsformen", "Die Aussage ,Das Ding ist' hat [...] keinen Sinn, wenn man aktuelles Bewusstsein [...] leugnen wollte». Hua XXXVI, pp. 19 e 64.

(7) «Der transzendentale Idealismus sagt: Eine Natur ist nicht denkbar ohne mitexistierende Subjekte möglicher Erfahrung von ihr; es genügen nicht mögliche Erfahrungssubjekte». Hua XXXVI, p. 156. 
sem aparição, fechado sobre o seu «em si», que não é já para ninguém, será um real que não se distinguirá do puro nada, portanto, um real que perdeu as suas Realitätsformen, na expressão do próprio Husserl, pois, para as distinguir e relevar, será necessário fazer regressar uma consciência dessas formas, que as possa asserir a partir de uma experiência actual. "Quando não há pura e simplesmente uma consciência, é então pensável o ser das coisas, o ser de uma Natureza, que, porém, é o que é, haja ou não alguém que a percepcione, represente ou pense? Eu digo: Não!»(8).

Esta correlatividade estrita entre Ser e Consciência actual não é, contudo, ainda o momento mais profundo da radicalização do conceito de Fenomenologia. Se um real não é sem conexão com uma consciência actual, que dele faça experiência, o inverso não é verdadeiro: uma vida de consciência é, em si mesma, pensável sem experiência actual de um mundo e sem posição de uma realidade. É justamente esse segundo elemento, que desequilibra a correlatividade entre Ser e Consciência, que se expressa no Gedankenexperiment de uma Weltvernichtung, de uma «aniquilação do mundo", que surge num célebre parágrafo das Ideen, de 1913.(9) Husserl desenvolve, nesse parágrafo, uma experiência de pensamento para exibir o ser absoluto da consciência, e a apodicticidade da doação imanente do fluxo de vivências, perante o carácter contingente do mundo e de todo ser posto. O pensamento director é, aí, a ideia de uma experiência que progredisse não segundo a forma da concordância e da progressiva sedimentação do sentido, de tal modo que as sucessivas posições de existência se confirmassem e reforçassem mutuamente, mas antes uma experiência em que cada novo acto viesse não confirmar, mas infirmar o anterior, que progredisse sob a forma permanente da contradição, uma experiência cuja unidade «explodisse» a cada momento em actos mutuamente incompatíveis, de tal modo que, ao longo

(8) «Ist Sein von Dingen, Sein einer Natur, die doch ist, was sie ist, ob irgendjemand sie wahrnimmt, vorstellt, denkt oder nicht, denkbar, wenn es schlechthin kein Bewusstsein gibt? Ich sage: «Nein!»». Hua XXXVI, p. 53.

(9) Hua III, pp. 103 e sgs. 
do seu decurso, nada apareceria, nenhum mundo e nenhuma experiência unitária do mundo se configurariam e só seria dado, como resíduo deste desmoronamento do mundo na experiência discordante, o próprio fluxo imanente da consciência na sua presença para si próprio. A lição deste Gedankenexperiment é clara: o mundo não é pensável sem uma consciência actual, mas a consciência é pensável sem uma experiência de mundo - a consciência pode ser Weltlos: sem mundo.

Esta dupla tese metafísica sobre a correlatividade entre Ser e Consciência e sobre a absolutez da segunda perante a contingência do primeiro repercutese em diversas instâncias e determina uma reformulação do tema e do método da Fenomenologia.

Primeiro, é a própria determinação da Consciência que sofre uma profunda reformulação. De facto psicológico inserido no mundo, ela torna-se agora a instância para a qual há — ou pode haver — um mundo. A Consciência de que a Fenomenologia trata não é mais determinável como uma realidade psicológica, mas antes como uma condição transcendental de toda a experiência: "a consciência não é nenbum ser real, mas antes a condição de toda realidade». (10) As vivências intencionais são, doravante, libertas da apercepção psicológica, que as põe como facto de uma psique, e esta como facto de um mundo, e apreendidas como fenómenos puros, formas essenciais da consciência de objectos, libertas de toda a factualidade contingente. A Fenomenologia não é, assim, Psicologia Descritiva, mas Filosofia Transcendental. Num projecto de carta a Cornelius, de 1906, Husserl expressa claramente esta alteração: "Equivoquei-me grosseiramente quando identifiquei Fenomenologia e Psicologia Descritiva (imanente) - de há quatro para cinco anos, advirto constantemente os meus alunos para esse erro». (11)

(10) "Bewusstsein ist aberkein Reales, sondern die Bedingung aller Realität». Hua XXXVI, p. 20 .

(11) «Ich habe mich selbst gröblich missverstanden, als ich Phänomenologie und deskriptive (immanente) Psychologie identifiziert habe. Seit vier bis fünf Jahren warne ich meine Schuler 
Segunda transformação: a descrição do fenómeno puro não será, doravante, a simples descrição psicológica de um acto, mas a descrição fenomenológica da correlação entre acto e sentido objectual. Na primeira década do século, Husserl tenta várias soluções terminológicas para incorporar este lado objectual da intencionalidade, que a primeira versão da Fenomenologia tinha ainda ignorado. Trata-se do lado "ôntico" ou "fânsico» do intencional, em oposição ao seu lado "Ontológico» ou "fansiológico». Mas a terminologia que se fixará será a das Ideen, que falam de uma dimensão noemática e de uma dimensão simplesmente noética da intencionalidade. Pouco importa a terminologia. A razão profunda desta reformulação do conceito de intencionalidade é que, a partir do momento em que a Consciência se liberta da sua apercepção psicológica, ela não é apenas consciência que se confronta com os objectos do mundo actual, mas que contém em si as formas e as estruturas de sentido de quaisquer objectos possíveis, mesmo que, a limite, nenhum mundo actualmente existente se configure numa experiência, como o ensinou o pensamento de uma Weltvernichtung. Esta incorporação do cogitatum no cogito, que é outra formulação husserliana da mesma tese, implica, por si só, uma extensão do projecto inicial das Logische Untersuchungen. Em vez de uma simples gramática pura das significações, surge, agora, o seu prolongamento noemático numa ontologia formal. Em vez de simples leis de compatibilidade e de incompatibilidade semântica entre significações, surge, agora, o seu prolongamento noemático numa ontologia material, que traça os contornos de sentido das diversas regiões possíveis do Ser. O conceito que organiza esta transformação é o de constituição. Todo o ser que pode ser visado e dado constitui-se, quanto ao seu sentido, em actos de consciência de que ele é, justamente, o correlato. A Fenomenologia é, agora, uma análise correlativa, que se desenvolve sob o conceito de uma constituição do sentido objectual em actos de consciência, p. 441 . 
independentemente de qualquer facto acerca da existência de um mundo actual. O conceito de doação continua operante, mas ele é agora sobredeterminado pelo de constituição - a doação evidente de um objecto tem subjacente uma actividade constituinte que abre o próprio espaço dessa doação. A Fenomenologia é, doravante, uma inspecção sistemática da constituição de todo objecto na consciência, e exibe essa correlatividade estrita entre acto e objecto sob a forma de um a priori ontológico, tanto material como formal.

É esta radicalização metafísica da conexão entre Sein e Bewusstsein que despoleta a segunda formulação do Método, que começou a desenhar-se nas Fünf Vorlesungen, de 1907, e culminou nas Ideen, de 1913. O regresso à consciência constituinte não é mais a focalização num ser do mundo, numa psique humana, mas numa instância que possibilita a experiência de quaisquer mundos, actuais ou possíveis. O regresso a essa instância exprime-se como uma suspensão da tese do mundo e da compreensão psicológica da consciência. À redução eidética das Logische Untersuchungen, vem somar-se, pois, a epoche e a redução transcendental. Ela implica uma correspondente extensão da redução eidética dos actos, em que ela fora primeiramente fixada, até os objectos que são seus correlatos. Há, doravante, não apenas o eidos da "espécie de acto", mas um eidos "Natureza», um eidos «realidade espácio-temporal», um eidos «valor», etc. A Fenomenologia é, agora, enquanto análise eidética da correlação noético-noemática, uma inspecção das formas possíveis de objectos e dos mundos de experiência possíveis, ou seja, do a priori ontológico material e formal, em que o mundo actual, que a redução põe entre parênteses e que a Weltvernichtung mostra não ser um absoluto, se insere apenas como um caso. "Assim, perante a «ciência pura da Natureza», accionamos nós, com toda esta Metafísica, e certamente Metafísica geral, enquanto ontologia apriorística da Natureza, a redução do $\mathrm{Ð}<$ ao absoluto, à consciência. Agora, podemos estabelecer a tarefa de uma doutrina de essência do conhecimento, por conseguinte, que percorra todos os tipos de conhecimento e todos os tipos correlatos de objecto, cuja 
doutrina de essência está presente na ontologia apriorística (a Lógica pura, no sentido mais alargado)».(12)

A análise correlativa ensina que toda e qualquer consciência é consciência em que se constitui o sentido de uma objectividade possível, e que isso em conjunto se integra num a priori ontológico. A suspensão da tese do mundo ensina, de seguida, que essa estrutura apriorística não carece de se efectivar numa experiência concordante de um mundo actual para justificar a sua legalidade própria. Ela diz respeito à essência e não ao facto. A possibilidade precede toda a actualidade, como o repetirá incessantemente Husserl.

IV

O terceiro momento de radicalização da Fenomenologia condensa-se nesta tese: todo a priori ontológico, tanto material como formal, e todo ser que, no horizonte dessa legalidade, possa ser posto como efectivo numa experiência concordante, é resultado de uma instituição primitiva de sentido (Urstiftung), que tem na vida subjectiva a sua génese última.

Esta terceira radicalização do conceito de Fenomenologia inicia-se na segunda década do sec. XX e está bem condensada numa curta frase do Husserl tardio: «O ego vive e precede todo ser efectivo e possível, e o ser de todo sentido, quer real quer irreal». (13)

A formulação anterior do conceito de Fenomenologia centrava-se em duas teses de fundo: primeiro, a correlatividade entre consciência e

(12) «So treiben wir mit alledem Metaphysik, und zwar allgemeine Metaphysik gegenüber der "reinen Naturwissenschaft» als apriorischer Ontologie der Natur: die Reduktion des $Đ<$ auf das Absolute, das Bewusstsein. Nun können wir die Aufgabe stellen einer Wesenslehre der Erkenntnis, also alle Erkenntnisarten durchgehen und alle korrelaten Gegenstandsarten, deren Wesenslehre vorliegt in der apriorischen Ontologie (der reinen Logik im weitesten Sinn)». Hua XXXVI, pp. 37-38.

(13) «Das ego lebt und geht allem wirklichen und möglichen Seienden voran, und Seiendes jedes, ob realen oder irrealen Sinn». Ms. D 17, p. 21a (1934). 
sentido objectivo (era a análise noético-noemática); segundo, a absolutez da consciência, e dessa correlatividade entre acto e sentido objectual, perante a contingência de qualquer mundo possível ou actual (era a epoche fenomenológica, suportada na experiência da Weltvernichtung). Esta dupla tese continha, porém, uma tensão no seu interior. É a resolução dessa tensão que despoleta esta nova radicalização da Fenomenologia.

A sua direcção fundamental é a seguinte: trata-se de regredir da correlatividade noético-noemática da consciência, e do a priori ontológico daí resultante, até o dinamismo da Vida da subjectividade absoluta, e de surpreender nesta a génese de todo o sentido e, por conseguinte, do próprio a priori ontológico em que a Fenomenologia se havia anteriormente fixado. Notemos as diferenças que nascem desta nova radicalização. Primeiro, a palavra-chave já não é Bewusstsein, mas Leben. Segundo, a vida subjectiva não é posta em correlação, mas anteposta a todo a priori ontológico-objectual. Terceiro, a relação da vida com o sentido objectual, ou seja, com as estruturas puras da consciência de objecto, é a de uma génese. A vida subjectiva, para que a Fenomenologia agora recua, não é apenas «anterior» a todo ser e todo sentido, ela é o lugar da sua instituição originária.

Esta radicalização da Fenomenologia organiza-se a partir do conceito director de Urstiftung, de instituição primitiva de sentido, e não já a partir dos anteriores conceitos de doação e de constituição, que são agora sobredeterminados por ele, tal como o conceito de "constituição" havia, antes, sobredeterminado o conceito de "doação». Esta nova radicalização da Fenomenologia é aquilo que o próprio Husserl designou, a partir dos anos vinte, como uma fenomenologia genética.

Ela implica uma nova reformulação do Método de análise intencional e essa reformulação tem, por detrás, como pensamento director, precisamente a tese Metafísica de uma resolução de todo o sentido objectivo na produtividade da Vida subjectiva. É neste quadro que, relativamente ao a priori formal, antes simplesmente estabelecido como uma legalidade eidética pura, desponta, agora, o projecto de uma genealogia da lógica. Esta genealogia está apontada 
a mostrar o surgimento das objectividades categoriais e dos conceitos puros de objecto a partir do domínio anterior da constituição passiva, enquanto campo de uma experiência antepredicativa. Relativamente ao a priori material, mais do que regiões de Ser, trata-se de exibir a génese originária, a partir das prestações intencionais da vida subjectiva, das significações materiais, como a de Natureza, coisa espacial e temporal, etc., e das idealidades sobre elas construídas, tal como o espaço da intuição geométrica, a figura, o número, etc. Deste ponto de vista radicalizado, é possível surpreender as Urstiftungen, ou seja, as instituições primitivas de sentido em que um mundo se constitui com as suas diversas regiões de ser, e o modo como as idealizações matemática e geométrica, que têm aí também o seu lugar de surgimento, reconfiguram esse mundo pela «substrução» de uma Natureza «exacta» e de uma Ciência que lhe corresponde. Esta regressão encontra, assim, uma génese de todo o sentido objectivo a partir da vida subjectiva e de um fundo último de constituição passiva, governada pelos conceitos de «estímulo» (Reiz), "afecção» (Affektion), "voltar-se-para» atentando (Zuwendung) e de "captação"(Erfassung), sobre o qual desponta a espontaneidade da génese activa. (14) o domínio de referência é, aqui, o da experiência prépredicativa e do Lebenswelt, o mundo-da-vida.

Mas esta figura genética da Fenomenologia permite, também, rever em profundidade o conceito de Fenomenologia das Ideen e marcar os seus limites. No próprio balanço de Husserl, essa Fenomenologia, centrada no tema da correlatividade entre Ser e Consciência, era ainda uma análise estática, uma simples taxionomia dos sentidos objectuais, incapaz de regredir do fio-condutor do objecto até a génese subjectiva que o suporta. Ela era, por isso mesmo, uma Fenomenologia para a qual o a priori ontológico era um dado último e inultrapassável: "A Fenomenologia desenvolvida no início é simplesmente "estática», as suas descrições são análogas às da

(14) Sobre estes conceitos, ver Erfahrung und Urteil. Hamburg: Felix Meiner Verlag, $1985^{6}$. 
história natural, que se concentra nos tipos singulares e, quanto muito, os sistematiza ordenando. Questões sobre a génese universal e sobre a estrutura genética do ego na sua universalidade, que vão para lá da forma temporal, permanecem ainda longínquas, já que elas são, de facto, questões de grau superior». (15) Agora, trata-se de dissolver esse a priori ontológico na produtividade da vida, e de exibi-lo como uma construção de sentido governada pela motivação de uma vida segundo a forma da razão. Por aí se descobre, por fim, uma historicidade, imanente à própria vida, que suporta este processo de instituição primitiva, de sedimentação e de transmissão do sentido. Esta dimensão histórica da vida subjectiva não é, ainda, a historicidade empírica das formações da cultura. Ela é uma génese ideal de todo sentido, a partir da operatividade da vida subjectiva, de uma maneira tal que todo o sentido constituído aparece como auto-realização e auto-explicação da subjectividade transcendental.

Eis o modo como a Fenomenologia genética, ao recuar mais além do sentido objectivo até a vida da «subjectividade absoluta», resolve a tensão interna do conceito anterior de Fenomenologia, dissolvendo o a priori ontológico na produtividade da vida subjectiva, e regredindo da análise correlativa até a historicidade da vida e a uma teoria geral da génese.

\section{V}

Derradeira reformulação da Fenomenologia: a instância que se descobre como lugar último de toda a constituição é "facto absoluto» (absolute Tatsache).

(15) "Die zunächst ausgebildet Phänomenologie ist bloss "statische», ihre Deskriptionen sind analog den naturhistorischen, die die einzewlnen Typen nachgehen und sie allenfalls ordnend systematisieren. Fragen der universalen Genesis und der über die Zeitformung hinausgehenden genetischen Struktur des Ego in seiner Universalität bleiben noch fern, wie sie ja in der Tat höherstufige sind». Hua I, p. 79. 
Como regressão à Consciência e, de seguida, às prestações da Vida, a Fenomenologia sempre se deu a si própria um campo positivo de análise descritiva - precisamente o da subjectividade, para si mesma presente numa evidência adequada e, em parte, também apodíctica. A vida está para si própria presente como um domínio de «ser absoluto» - é essa a lição da segunda reformulação da Fenomenologia —, e esse ser absoluto da vida autoconstitui-se como um Lebensström, uma "corrente de vida", aberta sobre os horizontes do passado e do futuro da temporalidade imanente. Mas esta determinação da Vida subjectiva não é ainda a derradeira. A auto-aparição da Vida sob a forma de um curso temporal deixa ainda por determinar o modo como se efectiva a sua temporalização numa corrente de vivências, e como ela pode a si própria aparecer como um fluxo estendido no tempo.

Ao visar-se a si mesma no horizonte da temporalidade imanente, a vida está presente no seu passado, mas a vida não é no passado. Ela antecipa-se para o futuro, mas a vida não é vida no futuro. Toda a vida subjectiva se efectiva num presente estacionário, proto-modal (Ur-modal), como diz Husserl, já que este presente sempre é, não passa para o passado, nem se anunciou nunca num futuro. Ele é um nunc stans, um "agora permanente», como forma nunca perempta de efectivação da vida de consciência. Esta é, de facto, de ponta a ponta, vida que sempre se desenrola num perpétuo presente. No «interior» desse Presente Estacionário, escoam os «agora»e constituem-se os horizontes de futuro e de passado, mas este presente não é um "agora», que vem e passa, não foi antes num futuro, não será nunca um passado. É nele que se contém a forma primitiva da Vida subjectiva, a partir da qual se constitui a forma do tempo imanente e as vivências, como objectos temporais no seu interior. Ele está, portanto, na origem da autoconstituição da vida como esse "absoluto último e verdadeiro" que a segunda radicalização da Fenomenologia havia fixado. Trata-se, agora, de ir mais além e de mostrar como pode ter a Fenomenologia diante de si esse campo de ser absoluto. 
É este último regresso que Husserl enceta, no final dos anos vinte e no início dos anos trinta, pelo desenvolvimento de uma nova operação do Método, que designa como «redução radicalizada». Enquanto a redução fenomenológica encetava o regresso ao Bewusstseinsström, a redução radicalizada é um recuo dessa corrente temporal de vivências até a instância em que ela se constitui e dá para uma evidência adequada. A redução radicalizada deve, pois, suspender os horizontes temporais da vida e exibir o modo da sua autoconstituição a partir do Presente Estacionário, que envolve toda a vida de consciência. Ela é, assim, uma regressão metódica que, pela suspensão da corrente de vivências, pretende recuar até o presente vivo pré- e pró-temporal, até o que Husserl designa como lebendige strömende Gegenwart.

Duas reformulações maiores estão contidas nesta derradeira radicalização da Fenomenologia.

Primeiro, este Eu do presente vivo e fluente eclipsa-se para a análise descritiva. Ele é pré-ser, visto que é a instância por onde se constitui o "ser absoluto" da consciência; ele é pré-temporal, visto que é o lugar de constituição do fluxo de consciência; ele é pré-reflexivo, visto que a reflexão implica a ontificação de uma vivência e a sua constituição como objecto temporal. O Ur-Ich do lebendige Gegenwart já não é, assim, exibível para a descrição. No entanto, ele é a mais próxima de todas as instâncias, pois ele é a própria presença da vida subjectiva, o estar postado do sujeito, ou seja, o seu estar no seu posto, sem que esse estar-posto reenvie, ao modo de Fichte, para uma qualquer Tathandlung.

Segundo, enquanto a Fenomenologia havia privilegiado a possibilidade sobre a efectividade, ${ }^{(16)}$ se tinha desenvolvido como descrição eidética de mundos possíveis e dos "eu» que nesses mundos funcionavam como sujeitos de experiência, este Eu do lebendige Gegenwart só como facto, e como facto

(16) Por exemplo: "Die alte ontologische Lehre, dass die Erkenntnis der "Möglichkeiten" der der Wirklichkeiten vorhergehen müsse, ist [...] wofern sie recht verstanden und in rechter Weise genacht wird, eine grosse Wahrheit». Hua III-1, p. 178. 
absoluto pode ser caracterizado. Toda a variação eidética, toda a passagem do Ego ao eidos-Ego, toda a doutrina dos possíveis, está ancorada no Ego fáctico que opera essas variações e constantemente ultrapassa a actualidade em direcção à possibilidade. A exibição do Ego do lebendige Gegenwart é, assim, a concentração numa facticidade primeira e inultrapassável, porque ela está na origem e é a base de todos os sistemas possíveis de experiência, de todos os mundos possíveis e de todas as objectividades constituídas, que podem ser obtidas por livre variação. Esse facto é sem-razão. Ele é a própria irrupção da instância para a qual pode, em geral, haver mundo, tanto o actual como os possíveis, e essa instância não é já reenviável para qualquer actividade ou passividade constituinte. Ela é o primitivo, impregnado de uma paradoxal "contingência necessária», que vem baralhar a própria lógica das modalidades.

Husserl di-lo em muitos manuscritos de trabalho. Leiamos apenas este: "O próprio absoluto é este presente universal primitivo, nele "reside» todo
tempo e todo mundo em qualquer sentido. [...] «Facto absoluto» - a palavra
"facto» está, aqui, empregue segundo o seu sentido invertido, do mesmo modo
que "coisa-de-facto» [Tatsache], aqui não há nenhum fautor. Ele é precisamente
o absoluto, que nem sequer como «necessário» pode ser caracterizado, o qual
reside na base de todas as possibilidades, todas as relatividades, todas as
condicionalidades, é doador do seu sentido e ser. [...] Este absoluto transporta
em si [...] o absoluto como «irrazão», como sistema do ser absoluto sem-razão,
sem a qual o racional "é impossível». (17)

(17) «Das Absolute selbst ist diese universale urtümliche Gegenwart, in ihr «liegt» alle Zeit und Welt in jedem Sinn. [...] "Absolutes Faktum». Das Wort Faktum ist seinem Sinn nach verkehrt hier angewendet, ebenso "Tatsache", hier ist kein Täter. Es ist eben das Absolute, das auch nicht als "notwendige» bezeichnet werden kann, das allen Möglichkeiten, allen Relativitäten, allen Bedingtheiten zugrunde liegend, ihnen Sinn und Sein gebend ist. [...] Dieses Absolute trägt in sich [...] das Absolute als "Unvernunft", als System des vernuntlosen absoluten Seins, ohne die Vernünftiges "unmöglich ist».» Hua XV, pp. 668-669. 
O caminho de pensamento de Edmund Husserl é, no seu conjunto, como que uma magnífica, poderosa, «arqueologia» da subjectividade, expondo-a em estratos cada vez mais primitivos, numa regressão que é um dos mais geniais exercícios de radicalidade de toda a tradição filosófica. Da consciência psicológica até a correlação entre ser e consciência transcendental, desta, até a vida, como lugar de constituição de todo sentido objectual, e, por fim, da vida até o Eu do presente vivo e fluente, como facto primitivo e absoluto, para lá do qual não é possível regredir. São estes quatro momentos que comandam as sucessivas reformulações do Método - primeiro, a simples redução eidética, de seguida, a redução transcendental, depois, a fenomenologia da génese, tanto passiva como activa, e, por fim, a redução radicalizada. Foi a esta articulação que chamámos, precisamente, a Metafísica do Método. 


\section{Série}

\section{Documentos}

Imprensa da Universidade de Coimbra

Coimbra University Press

2007

- U

C • 